\title{
An alternative to civil disobedience for concerned scientists
}

To the Editor - Charlie Gardner and Claire Wordley recently urged environmental scientists of various stripes to undertake acts of civil disobedience or, at least, to support such acts by others ${ }^{1}$. It is, they assert, a "moral duty" to "act on our own warnings to humanity" and "join the popular movements demanding political action". As members of Extinction Rebellion who are frustrated by the yawning 'science-policy' gap, the duo present civil disobedience of the sort James Hansen has engaged in as a circumstantial necessity. Otherwise, those in power will continue to ignore the profoundly inconvenient truths of the science, while protest movements may lack sufficient scientific credibility without experts among their number.

While civil disobedience can certainly be a key driver of structural shifts in any country, Gardner and Wordley's clarion call strikes the wrong note. Environmental scientists are expected to supply answers to cognitive questions not normative ones. Their public authority depends greatly on not conflating the two. They are not analogous to cancer specialists recommending treatment to a patient at risk of death. Yes, the Earth system is being forced to change significantly courtesy of human actions. But the meaning of this 'wicked problem' and the basket of possible solutions must be determined by politicians, businesses and citizens. It is not, and will not be, universally recognized as a 'crisis' or a 'catastrophe', however frustrating that may be to many concerned scientists.

Those of us in the research community who want to see profound socioeconomic and cultural change are entitled to be dismayed by the foot dragging of Donald Trump, Scott Morrison and other political leaders. But as scientists, there is another option to civil disobedience. We need a major drive towards scientific inquiry that is directly framed by political goals and policy options, such as those related to the Sustainable Development Goals. This involves working closely with social scientists and humanists, and with non-academic stakeholders, to identify alternative future scenarios predicated on diverse human values and goals. The practical and technological means of achieving these goals is a scientific question properly predicated on normative reasoning and possessed of normative implications. Answering questions about means in the light of values and goals requires rigorous inquiry. But which values and goals win out in the medium-to-long term is, in the widest sense, a political matter not a scientific one. The cognitive-normative distinction is these days a delicate one, but maintaining it matters for science and the wider society.

Future Earth, the new platform for global change research, is one of several arenas where attempts are being made to make environmental science speak to questions of politics and policy. Another is the Intergovernmental Platform on Biodiversity and Ecosystem Services. The Intergovernmental Panel on Climate Change may well evolve in this direction, as Working Group III assumes increased importance. Such arenas allow scientists to use their skills to good effect without them politicizing their expertise unduly and thereby risking science's credibility.

Noel Castree (iD)

Department of Geography, Manchester University, Manchester, UK.

e-mail:noel.castree@manhester.ac.uk

Published online: 28 October 2019

https://doi.org/10.1038/s41559-019-1023-y

References

1. Gardner, C. J. \& Wordley, C. F. R. Nat. Ecol. Evol. 3, 1271-1272 (2019).

Competing interests

The author declares no competing interests. 